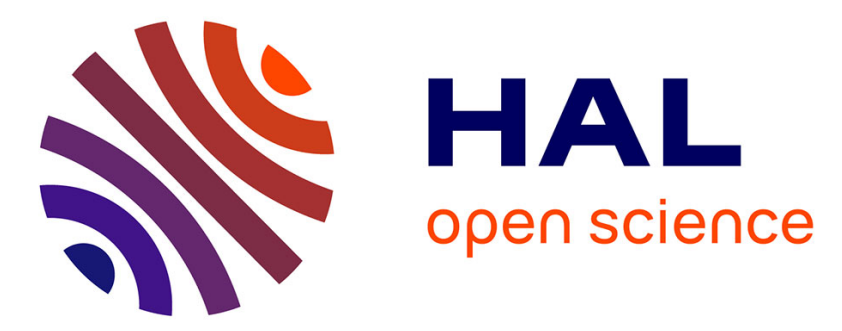

\title{
SO_2 conversion to sulfones: development and mechanistic insights of a sulfonylative Hiyama cross-coupling
}

Aurélien Adenot, Joëlle Char, Niklas von Wolff, Guillaume Lefevre, Lucile Anthore-Dalion, Thibault Cantat

\section{To cite this version:}

Aurélien Adenot, Joëlle Char, Niklas von Wolff, Guillaume Lefevre, Lucile Anthore-Dalion, et al.. SO_2 conversion to sulfones: development and mechanistic insights of a sulfonylative Hiyama cross-coupling. Chemical Communications, 2019, 55, pp.12924-12927. 10.1039/C9CC06858A . cea02311034

\section{HAL Id: cea-02311034 https://hal-cea.archives-ouvertes.fr/cea-02311034}

Submitted on 10 Oct 2019

HAL is a multi-disciplinary open access archive for the deposit and dissemination of scientific research documents, whether they are published or not. The documents may come from teaching and research institutions in France or abroad, or from public or private research centers.
L'archive ouverte pluridisciplinaire HAL, est destinée au dépôt et à la diffusion de documents scientifiques de niveau recherche, publiés ou non, émanant des établissements d'enseignement et de recherche français ou étrangers, des laboratoires publics ou privés. 


\title{
$\mathrm{SO}_{2}$ Conversion to Sulfones: Development and Mechanistic Insights of a Sulfonylative Hiyama Cross-Coupling
}

\author{
Aurélien Adenot, ${ }^{a}$ Joëlle Char, ${ }^{a}$ Niklas von Wolff, ${ }^{a}$ Guillaume Lefèvre, ${ }^{a}$ Lucile Anthore-Dalion, ${ }^{a}$ \\ Thibault Cantat ${ }^{\mathrm{a} *}$
}

\begin{abstract}
A sulfonylative Hiyama cross-coupling reaction using gaseous $\mathrm{SO}_{2}$ is described, using Pd-catalysts. The use of silicon-based nucleophiles leads to the formation of allyl sulfones under mild conditions with a broad functional group tolerance. Control experiments coupled with DFT calculations shed light on the key steps of the reaction mechanism, revealing the crucial role of a transient sulfinate anion.
\end{abstract}

Present in many contemporary pharmaceuticals, agrochemicals and materials (e.g. the antibiotic Thiamphenicol or the herbicide Pyroxasulfone), sulfones are also used as key intermediates in organic synthesis ${ }^{1,2}$ (e.g. the Julia olefination ${ }^{3}$ or the Ramberg-Bäcklund reaction ${ }^{4}$ ). Given this combination of a prominent biological activity and an appealing synthetic utility, numerous methodologies have been developed for their preparation. ${ }^{1}$ Because it has a high atom-efficiency, the insertion of a sulfur dioxide molecule upon coupling a nucleophile with an electrophile has recently emerged as a valuable route. $^{5}$ Organomagnesium, $^{6}$ organozinc $^{7}$ and organoboron $^{8}$ compounds were successively reported as nucleophiles; yet, they suffer from toxicity issues, functional group incompatibility, and/or air-sensitivity. ${ }^{9}$

Because they are readily available, air-stable and show an improved functional-group tolerance, organosilanes were recently considered to produce sulfones from $\mathrm{SO}_{2}$ or $\mathrm{SO}_{2}$ surrogates. ${ }^{10}$ However, up-to-date methods are still limited to $\mathrm{sp}^{3}$-hybridized electrophiles, which react through $S$-alkylation after the formation of an intermediate sulfinate anion (Scheme 1). Unlocking the utilization of $\mathrm{sp}^{2}$-hybridized electrophiles would require a change of mechanism; and, to tackle this issue, we report herein the first sulfonylative Hiyama cross-coupling affording sulfones from organosilanes, sulfur dioxide and aryl iodides, in a single-step reaction (Scheme 1). Mechanistic

\footnotetext{
a. NIMBE, CEA, CNRS, Université Paris-Saclay, CEA Saclay, 91191 Gif-sur-Yvette, France.Email : thibault.cantat@cea.fr

Electronic Supplementary Information (ESI) available: [details of any supplementary information available should be included here]. See DOI: 10.1039/x0xx00000x
}

control experiments, combined with DFT calculations performed on the key reaction steps, provide insight into the mechanism of the reaction.

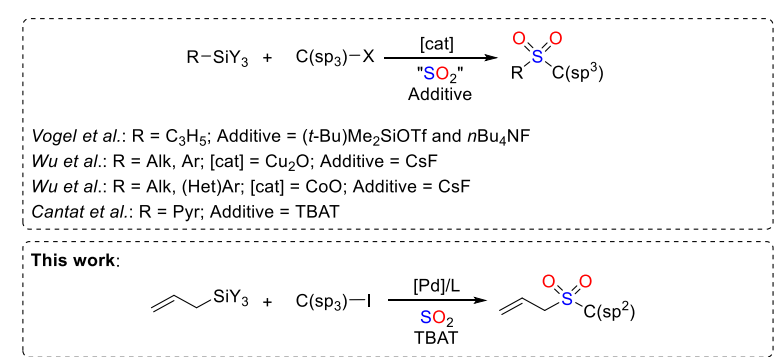

Scheme 1. Representative state-of-the-art of sulfone synthesis from $\mathrm{SO}_{2}$ and organometallic compounds.

Shortly after the discovery of the eponymous coupling, Hiyama et al. reported the carbonylative coupling of aryl iodides with organosilanes in the presence of a palladium catalyst (Figure 1a). ${ }^{11} \mathrm{SO}_{2}$ is both more electrophilic and nucleophilic than $\mathrm{CO},{ }^{12}$ and its frontier orbitals are centered on the sulfur atom as they are on the carbon atom of carbon monoxide (Figure 1c). Besides, the migratory insertion of $\mathrm{SO}_{2}$ in a $\mathrm{Pd}-\mathrm{C}$ bond has already been reported by Goddard and co-workers (Figure 1b). ${ }^{13}$ We hence hypothesized the feasibility of a sulfonylative Hiyama cross-coupling.

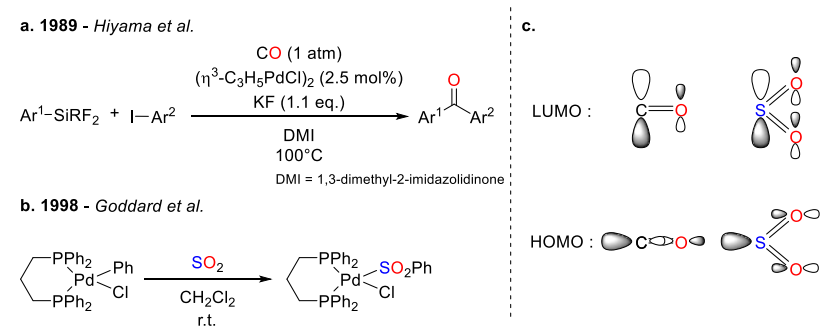

Figure 1. a) First example of a carbonylative Hiyama cross-coupling; b) Insertion of $\mathrm{SO}_{2}$ in a $\mathrm{Pd}-\mathrm{C}$ bond; c) Frontier orbitals of $\mathrm{CO}$ and $\mathrm{SO}_{2}$. 
Table 1. Influence of the reaction conditions on the sulfonylative Hiyama cross-coupling of triethoxy(allyl)silane (1a) with 4-iodotoluene (2) (see Table S1 for a more exhaustive table). ${ }^{\text {a }}$

\begin{tabular}{|c|c|c|c|c|}
\hline & & $(\mathrm{OEt})_{3}$ & O"s" & \\
\hline Entry & Fluoride source (eq.) & $\mathrm{SO}_{2}$ source (eq.) & Ligand (\%) & Yield in 3a (\%) \\
\hline 1 & $\mathrm{TBAF} \cdot 3 \mathrm{H}_{2} \mathrm{O}(1)$ & $\mathrm{SO}_{2}{ }^{\mathrm{b}}(1)$ & - & 12 \\
\hline 2 & $\mathrm{TBAF} \cdot 3 \mathrm{H}_{2} \mathrm{O}(1)$ & DABSO (0.5) & - & 0 \\
\hline 3 & TBAT (1) & $\mathrm{SO}_{2}{ }^{\mathrm{b}}(1)$ & - & 17 \\
\hline 4 & TBAT (1) & $\mathrm{SO}_{2}{ }^{\mathrm{b}}(2)$ & - & 26 \\
\hline 5 & TBAT (1) & $\mathrm{SO}_{2}{ }^{\mathrm{b}}(4)$ & - & 0 \\
\hline 6 & TBAT (1) & $\mathrm{SO}_{2}{ }^{\mathrm{b}}(2)$ & XPhos (10) & 41 \\
\hline 7 & TBAT (1) & $\mathrm{SO}_{2}{ }^{\mathrm{b}}(2)$ & Xantphos (10) & 78 \\
\hline 8 & TBAT (1) & $\mathrm{SO}_{2}{ }^{\mathrm{b}}(2)$ & Xantphos (5) & 65 \\
\hline 9 & TBAF (1M in THF) (1) & $\mathrm{SO}_{2}{ }^{\mathrm{b}}(2)$ & Xantphos (10) & 71 \\
\hline
\end{tabular}

a Results obtained in THF at $80{ }^{\circ} \mathrm{C}$ during $4 \mathrm{~h}$ on a $0.1 \mathrm{mmol}$ scale. ${ }^{b} \mathrm{SO}_{2}$ was generated by thermal decomposition of $\mathrm{K}_{2} \mathrm{~S}_{2} \mathrm{O}_{5}$, see $\mathrm{Supporting}$ Information. TBAF $=$ tetrabutyl ammonium fluoride; TBAT = tetrabutylammonium difluorophenyl-silicate. Yields measured by ${ }^{1} \mathrm{H}$ NMR (internal standard: mesitylene).

We began our investigation by exploring the coupling of triethoxy(allyl)silane (1a), 4-iodotoluene (2), and gaseous sulfur dioxide, generated by thermal decomposition of $\mathrm{K}_{2} \mathrm{~S}_{2} \mathrm{O}_{5}$ in a two-chamber apparatus (see Supporting Information). In the presence of $\mathrm{Pd}(\mathrm{acac})_{2}$ as a catalyst and TBAF $3 \mathrm{H}_{2} \mathrm{O}$ as a fluoride source to activate the weakly polar $\mathrm{C}-\mathrm{Si}$ bond, the desired sulfone 3a was obtained in $12 \%$ yield (Table 1 , entry 1 ). By contrast, the bench stable surrogate of $\mathrm{SO}_{2}, \mathrm{DABSO}$, popularized by Willis et al., ${ }^{14}$ gave no desired product (Table 1 , entry 2 ), presumably due to the coordination of the DABCO by-product to palladium. Changing the fluoride source to the anhydrous tetrabutylammonium difluorophenyl-silicate (TBAT) improved the reaction efficiency ( $17 \%$ yield, Table 1 , entry 3 ). While two equivalents of $\mathrm{SO}_{2}$ increased the yield up to $26 \%$ (Table 1, entry 4 ), an excess of $\mathrm{SO}_{2}$ was detrimental to the reaction (Table 1 , entry 5), possibly because of a poisoning of the catalyst. After screening a variety of palladium sources and phosphine ligands (Table 1, entries 5-7 and Table S1), a set of conditions (Pd(acac) 5 mol\%, Xanthphos 10 mol\%, TBAT 1 eq.) gave the best results in our hands, yielding the desired sulfone $\mathbf{3 a}$ in $78 \%$ yield (Table 1 , entry 7 ). No reaction took place without the catalyst, even after $24 \mathrm{~h}$ (Table S1).

During the screening process, the diallyl sulfone (4) was identified as a side-product. The relative proportion of $\mathbf{4}$ was found to depend directly on the nature of the substituents at the silicon atom (Table 2): the quantity of diallyl sulfone (4) increases with the fluoride-affinity of the organosilane (computed by the Gibbs free energy variation for the fluoride transfer from $\mathrm{Me}_{3} \mathrm{SiF}_{2}{ }^{-}$to the allylsilane). As a result, tri(ethoxy)allyl silanes were selected to explore this new reaction, as it provides the best balance between selectivity and productivity (see $\mathrm{SI}$ ).
Table 2. Formation of the diallyl sulfone (4) as a side-product.

\begin{tabular}{|c|c|c|c|c|}
\hline${ }_{1}^{\mathrm{Si}}$ & $\begin{array}{r}\mathrm{Pd}(\mathrm{aca} \\
\text { Xantph } \\
\mathrm{TB} / \\
4\end{array}$ & $\begin{array}{l}\begin{array}{l}\mathrm{mol} \%) \\
\mathrm{mol} \%) \\
\mathrm{eq} .)\end{array} \\
\stackrel{{ }^{\circ} \mathrm{C}}{\longrightarrow}\end{array}$ & & 4 \\
\hline$Y_{3}$ & $\begin{array}{c}\text { Yield 3a } \\
\text { (\%) }\end{array}$ & $\begin{array}{c}\text { Yield } 4 \\
(\%)\end{array}$ & $\begin{array}{l}4 / 3 a \\
\text { ratio }\end{array}$ & $\begin{array}{c}\Delta \mathrm{G}^{\mathrm{a}} \\
\text { (kcal.mol-1) }\end{array}$ \\
\hline$(\mathrm{OMe})_{3}$ (1b) & 51 & 23 & 0.45 & 2.98 \\
\hline$(\mathrm{OEt})_{3}(1 \mathrm{a})$ & 78 & 10 & 0.13 & 3.60 \\
\hline $\mathrm{Me}_{2}(\mathrm{OMe})(1 \mathrm{c})$ & 74 & 7 & 0.09 & 11.94 \\
\hline $\mathrm{Me}_{3}(\mathrm{dd})$ & 54 & 0 & 0 & 15.60 \\
\hline
\end{tabular}

${ }^{a}$ Gibbs free energy variation for the fluoride transfer from $\mathrm{Me}_{3} \mathrm{SiF}_{2}-$ to allylsilanes 1 (see SI for computational details). Yields measured by ${ }^{1} \mathrm{H}$ NMR (internal standard: mesitylene).

The chosen reaction conditions enabled the synthesis of allyl arylsulfones $\mathbf{3 a - 3 e}$ from aryl iodides bearing electron-donating substituents as well as electron-withdrawing in 38-82\% yield. The reaction tolerates well the presence of a ketone group and 3e was formed in $45 \%$ yield. Interestingly, sulfones bearing electron-donating substituents $\mathbf{3 a} \mathbf{3} \mathbf{3} \mathbf{b}$ were obtained in better yields $(78-82 \%)$ than the ones bearing electron-withdrawing substituents (3d-3e, 38-45\%, Scheme 2a), as reflected by a Hammett correlation with a slope of $\rho=-0.39$ (Scheme 2b). Alkenyl sulfone $\mathbf{3 f}$ was also prepared in $57 \%$ yield (Scheme $2 a$ ). Using aryl bromides, diallyl sulfone (4) was exclusively formed, presumably due to the more difficult activation of the $\mathrm{C}-\mathrm{Br}$ bond by oxidative addition.

As regards the nucleophile, methyl-substituted allylsilanes $\mathbf{1 e}-$ $1 \mathrm{~g}$ successfully provided the desired sulfones in $33-74 \%$ yields, with the selective formation of the $\alpha$-substituted sulfones from the corresponding $\gamma$-substituted allylsilanes, while the classical Hiyama cross-coupling reaction using substituted allylsilanes usually faces regioselectivity issues. ${ }^{15}$ Disappointingly, triethoxy(phenyl)silane and triethoxy(vinyl)silane exhibited no reactivity (Scheme 3). 


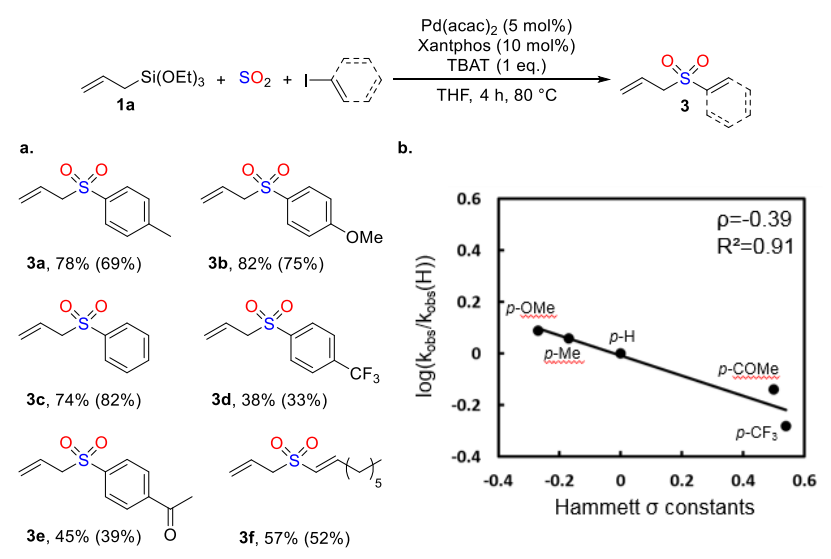

Scheme 2. a) Substrate scope in organoiodides; b) Hammett plot of the reaction Reaction conditions: electrophile (1 eq.), allylSi(OEt) ${ }_{3}$ (1a, 1.1 eq.), electrophile (1 eq.), $\mathrm{SO}_{2}$ (2 eq., generated by thermal decomposition of $\mathrm{K}_{2} \mathrm{~S}_{2} \mathrm{O}_{5}$, see $\mathrm{SI}$ ), TBAT (1 eq.), $\mathrm{Pd}(\mathrm{acac})_{2}$ ( 5 mol\%), Xantphos $(10 \mathrm{~mol} \%), \mathrm{THF}, 80^{\circ} \mathrm{C}, 4 \mathrm{~h}$. Yields measured by ${ }^{1} \mathrm{H}$ NMR (internal standard: mesitylene). Yields of isolated products from scaled-up experiments ( $1 \mathrm{mmol}$ scale) are given within parentheses.

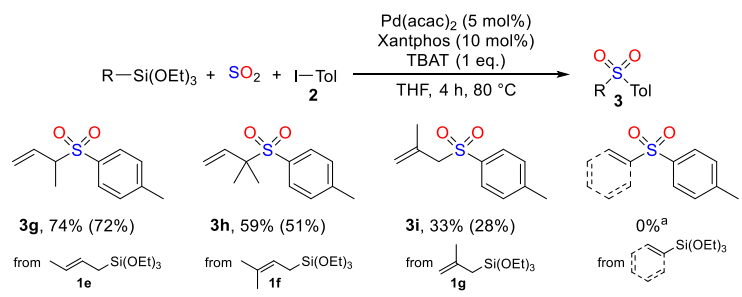

Scheme 3. Substrate scope in organosilanes. an the case of aryl- and vinylsilane, the nucleophile were fully recovered. Reaction conditions: organosilane (1.1 eq.), 4iodotoluene (2, 1 eq.), $\mathrm{SO}_{2}$ (2 eq., generated by thermal decomposition of $\mathrm{K}_{2} \mathrm{~S}_{2} \mathrm{O}_{5}$, see $\mathrm{SI}$ ), TBAT ( 1 eq.), Pd(acac) 2 (5 mol\%), Xantphos $(10 \mathrm{~mol} \%)$, THF, $80{ }^{\circ} \mathrm{C}, 4 \mathrm{~h}$. Yields measured by ${ }^{1} \mathrm{H}$ NMR (internal standard: mesitylene). Yields of isolated products from scaled-up experiments ( $1 \mathrm{mmol}$ scale) are given within parentheses. ${ }^{\ddagger}$

These surprising results prompted us to conduct mechanistic control experiments. The catalytic system is an efficient catalyst in Hiyama couplings and, in the absence of $\mathrm{SO}_{2}$, 1-allyl-4methylbenzene (6a) and biphenyl (6b) were formed from triethoxy(allyl)silane (1a) and triethoxy(phenyl)silane (5), respectively (Scheme $4 a$ ). Nevertheless, in the presence of $\mathrm{SO}_{2}$, sulfone 3 a was obtained in $78 \%$ yield, while the corresponding diarylsulfone $\mathbf{7}$ was not observed starting from phenylsilane $\mathbf{5}$. These observations demonstrate that the successful formation of sulfones $\mathbf{3 a - 3 i}$ cannot be explained by a direct transposition of the mechanism reported for carbonylative cross-couplings, ${ }^{16}$ where the insertion of the small molecule occurs after the oxidative addition (path $A$, Scheme $4 d$ ).

Careful ${ }^{1} \mathrm{H}$ NMR monitoring of the reaction revealed the formation of the allylsulfinate anion $\mathbf{8} \mathbf{a}$ as an intermediate (Figure S3). Another pathway was hence devised, where $\mathbf{8 a}$ is involved in a ligand exchange after an oxidative addition step (path $B$ in Scheme $4 d$ ). The desired sulfone 3 would then be obtained through a reductive elimination step.

To probe the role of transient sulfinate anions, the organosilane nucleophiles $1 \mathbf{a}$ and $\mathbf{5}$ were reacted with $\mathrm{SO}_{2}$ and ethyliodide, in the absence of the palladium catalyst. While sulfone 9a was formed in $85 \%$ yield from the allylsilane, only $4 \%$ of the ethylphenylsulfone $\mathbf{9 b}$ were observed, suggesting that the formation of phenylsulfinate from triethoxy(phenyl)silane (5) is blocked (Scheme 4b). This finding was confirmed when diarylsulfone 7 was obtained in $24 \%$ yield from the preformed arylsulfinate $8 \mathrm{c}$ was exposed to phenyl iodide, in the presence of the palladium catalyst (Scheme 4c). All together, these data support path B in Scheme 4d, with the metal catalyst enabling the coupling between a transient sulfinate anion and the arylhalide electrophile.
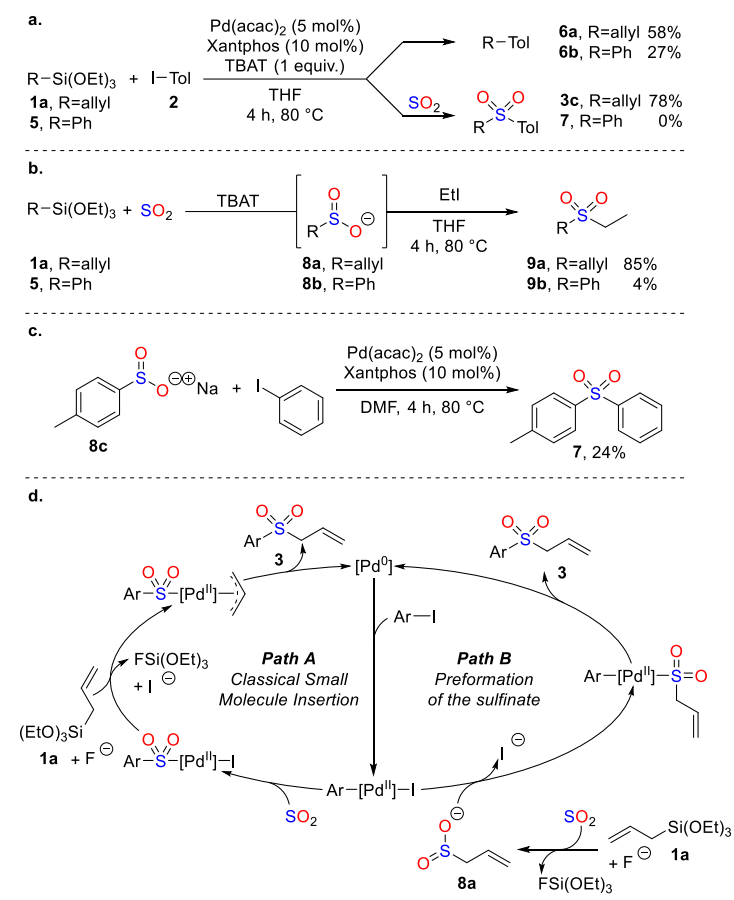

Scheme 4. Mechanistic control experiments: a) Comparison between Hiyama crosscoupling and the sulfonylative version; b) in situ sulfinate formation; c) Direct crosscoupling of aryl sulfinate $\mathbf{7 c}$ with phenyl iodide (DMF was used for solubility of $\mathbf{8 c}$, see SI for more details); d) Proposed pathways for the mechanism of the reaction. Yields measured by ${ }^{1} \mathrm{H}$ NMR (internal standard: mesitylene).

The regioselectivity observed with substituted allylsilanes (Scheme 3 ) readily derives from this mechanism. With an allylic nucleophile, the sulfinate formation can proceed through two different mechanisms: either a bimolecular electrophilic substitution at the $\alpha$ position of the silane $\left(\mathrm{TS}_{1}\right.$, Scheme 5$)$, or the corresponding $\mathrm{S}_{\mathrm{E}} 2^{\prime}$ mechanism with formation of the $\mathrm{C}-\mathrm{S}$ bond at the $\gamma$ position $\left(\mathbf{T S}_{2}\right.$, Scheme 5). DFT calculations revealed that the $S_{\mathrm{E}} 2^{\prime}$ path $\left(\Delta G^{\ddagger}\left(\mathbf{T S}_{\mathbf{2}}\right)=25.4 \mathrm{kcal} . \mathrm{mol}^{-1}\right)$ is favored over the corresponding ipso reaction $\left(\Delta G^{\ddagger}\left(\mathbf{T S}_{1}\right)=29.7 \mathrm{kcal} . \mathrm{mol}^{-1}\right)$. Besides in the case of trimethyl(aryl)silane, for which only $\mathbf{T S}_{\mathbf{1}}$ can be considered, the transition state lies $34.0 \mathrm{kcal}^{\mathrm{mol}} \mathrm{m}^{-1}$ higher than the starting materials, which explains its lack of reactivity.

In classical Hiyama cross-coupling reactions, the ratedetermining step (RDS) is usually the transmetallation. ${ }^{17}$ Here, the pre-formation of a sulfinate anion circumvents such a transmetallation and the $\mathrm{Pd}$-catalyst instead mediates the formation of the second $\mathrm{C}-\mathrm{S}$ bond, connecting the electrophile and the $\mathrm{SO}_{2}$ fragment. According to the Hammett plot (Scheme $2 b)$, the rate-determining step of the catalytic reaction is facilitated with electron-rich electrophiles $(\rho<0)$, suggesting that the rate-determining step is the reductive elimination, ${ }^{18}$ rather than the oxidative addition. ${ }^{19}$ 


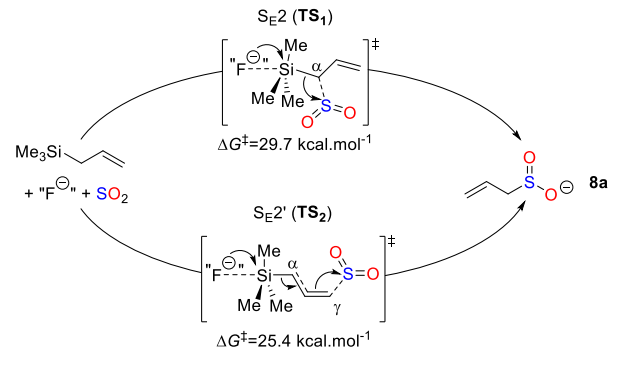

Scheme 5. Computed reaction pathways for the formation of the sulfinate via $\mathrm{S}_{\mathrm{E}} 2$ or $S_{E} 2^{\prime}$. Level of theory: B3LYP/G-D3/6-311+G(d) $(C, H, O)$ and 6-311++G(d,p) $(F, S, S i)$, PCM was used for THF solvation. Values given correspond to Gibbs free energies with respect to the starting materials $\left(G=0.0 \mathrm{kcal}^{\mathrm{mol}} \mathrm{mo}^{-1}\right.$. " $\mathrm{F}^{-1}$ " stands in fact for the anion $\mathrm{FSO}_{2}-. . \$$

In fact, the energy barrier computed for the reductive elimination of an allylsulfone from (allylSO $\left.{ }_{2}\right)-\mathrm{Pd}\left(\mathrm{PMe}_{3}\right)_{2}-\mathrm{Ph}$ is high, at $37.1 \mathrm{kcal}^{\mathrm{mol}}{ }^{-1}$ (compared to $23.2 \mathrm{kcal}^{\mathrm{mol}} \mathrm{m}^{-1}$ for allyl$\left.\mathrm{Pd}\left(\mathrm{PMe}_{3}\right)_{2}-\mathrm{Ph}\right)$. Importantly, the DFT calculations also point to the positive influence of electron-donating groups on the kinetics of this step, in agreement with the slope of the experimental Hammett plot (Figure 2). Hartwig et al. have shown that the formation of $\mathrm{C}-\mathrm{S}$ bonds by reductive elimination from $\mathrm{Pd}(\mathrm{II})$ thiolate complexes are, on the contrary, facilitated with electron-deficient aryl partners. ${ }^{20}$ The inverse trends may be attributed to the lower nucleophilicity of the sulfinate anion compared to the thiolate anion, the lone pair of the sulfur atom being partly delocalized on the two oxygen atoms (Figure 2 ).
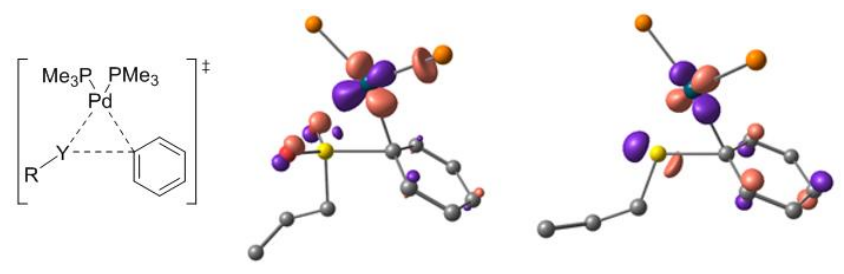

\begin{tabular}{|c|c|c|c|}
\hline & & $\mathrm{Y}=\mathrm{SO}_{2}$ & $Y=S$ \\
\hline $\mathrm{R}=\mathrm{CF}_{3}$ & $\uparrow \sigma$ & 37.5 & $24.4 \uparrow k$ \\
\hline $\mathrm{R}=\mathrm{H}$ & & 37.1 & 26.4 \\
\hline $\mathrm{R}=\mathrm{NMe}_{2}$ & & $34.2 \downarrow k$ & 27.9 \\
\hline
\end{tabular}

Figure 2. Representations of the HOMO in the transition states for the reductive elimination from (allylY)- $\mathrm{Pd}\left(\mathrm{PMe}_{3}\right)_{2}-\mathrm{Ph}$ (with $\mathrm{Y}=\mathrm{SO}_{2}$ or $\mathrm{S}$, hydrogens and methyl groups from $\mathrm{PMe}_{3}$ were omitted for clarity) and Gibbs free energy of the transition states $\left(\Delta G^{\ddagger}(\mathrm{TS})\right)$ with respect to the starting material $\left(G=0.0 \mathrm{kcal} . \mathrm{mol}^{-1}\right)$. Level of theory: B3LYP/G-D3/6-311+G(d) (C, H, O, N, F), 6-311++G(d,p) (P, S) and SDD (Pd), PCM was used for THF solvation.

In conclusion, we have developed a practical palladiumcatalyzed synthesis of allyl aryl sulfones from readily available organosilanes, aryl halides, and sulfur dioxide. This process represents the first approach that introduces a $\mathrm{sp}^{2}$-hybridized electrophile with an organosilane in a sulfonylative crosscoupling. Experimental and theoretical investigations have demonstrated the key role of transient sulfinate anions and their coupling with the aryl halides, mediated by palladium, and they highlight the challenges facing the synthesis of diaryl sulfones from organosilanes.
There are no conflicts to declare.

\section{Notes and references}

¥ As shown in Entry 9 of Table 1, TBAF (1M in THF) is a competent fluoride source and it was used for scaled-up experiments to avoid the formation of the allyl phenyl sulfone $\mathbf{3 c}$ from TBAT.

$\S$ As shown in the $\mathrm{SI}$, the unimolecular pathway has to be discarded, the fluoride transfer from the fluoride source to the organosilane and subsequent $\mathrm{C}-\mathrm{Si}$ bond scission of the hypervalent species being too energetically demanding.

$\S \S$ As already reported, ${ }^{10 d}$ and experimentally evidenced (see SI), the fluoride anion is actually transferred to $\mathrm{SO} 2$ to yield the stable anion $\mathrm{FSO}_{2}^{-}$which acts as the fluoride source.

1 G. Manolikakes, N.-W. Liu and S. Liang, Synthesis, 2016, 48, 1939.

2 B. M. Trost and C. A. Kalnmals, Chem. Eur. J., 2019, 25, 11193.

3 M. Julia and J.-M. Paris, Tetrahedron Lett., 1973, 14, 4833.

4 L. Ramberg and B. Bäcklund, Ark. Kemi. Minerat. Geol., 1940, 13A, 50.

5 D. Zheng and J. Wu, Sulfur Dioxide Insertion Reactions for Organic Synthesis; Springer: Singapore, 2017; Chapter 3.

6 A. S. Deeming, C. J. Russel, A. J. Hennessy, M. C. Willis, Org. Lett., 2014, 16, 150.

7 B. N. Rocke, K. B. Bahnck, M. Herr, S. Lavergne, V. Mascitti, C. Perreault, J. Polivkova and A. Shavnya, Org. Lett., 2014, 16, 154.

8 Y. Chen and M. C. Willis, Chem. Sci., 2017, 8, 3249.

9 Y. Nakao and T. Hiyama, Chem. Soc. Rev., 2011, 40, 4893.

10 a) L. Bouchez and P. Vogel, Synthesis, 2002, 2, 225; b) D. Zheng, M. Chen, L. Yao and J. Wu, Org. Chem. Front., 2016, 3, 985; c) D. Zheng, R. Mao, Z. Li and J. Wu, Org. Chem. Front., 2016, 3, 359; d) N. von Wolff, J. Char, X. Frogneux and T. Cantat, Angew. Chem. Int. Ed., 2017, 56, 5616.

11 Y. Hatanaka and T. Hiyama, Chem. Lett., 1989, 18, 2049.

12 M. Tiwari, Vinit and C. M. Ramachandran, Chem. Phys. Lett., 2019, 726, 111.

13 G. Pelzer, J. Herwig, W. Keim and R. Goddard, Russ. Chem. Bull., 1998, 47, 904.

14 H. Woolven, C. Gonzalez-Rodriguez, I. Marco, A. L. Thompson and M. C. Willis, Org. Lett., 2011, 13, 4876.

15 Y. Hatanaka, K.-i. Goda and T. Hiyama, Tetrahedron Lett., 1994, 35, 6511.

16 Y. Hatanaka, S. Fukushima and T. Hiyama, Tetrahedron 1992, 48, 2113.

17 C. Amatore, L. Grimaud, G. Le Duc and A. Jutand, Angew. Chem., 2014, 126, 7102.

18 A rate-determining reductive elimination is in addition compliant with the higher efficiency of Xantphos as a ligand (Table 1 and S1). Indeed, because of the steric pressure induced by its wide bite angle $\left(111^{\circ}\right)$, Xantphos is known to promote difficult reductive eliminations, notably with weakly nucleophilic partners. See: a) P. J. C. Kamer, P. W. N. M. Van Leeuwen and J. N. H. Reek, Acc. Chem. Res., 2001, 34, 895; b) V. V. Grushin and W. J. Marshall, J. Am. Chem. Soc., 2006, 128, 12644 ; c) K. Fujita, M. Yamashita, F. Puschmann, M. M. Alvarez-Falcon, C. D. Incarvito and J. F. Hartwig, J. Am. Chem. Soc. 2006, 128, 9044.

19 Troupel et al. showed that oxidative addition is facilitated with electron-poor electrophiles $(\rho>0)$ : J.-F. Fauvarque, F. Pflüger, M. Troupel, J. Org. Chem., 1981, 208, 419.

20 G. Maan, D. Baranano, J. F. Hartwig, A. L. Rheingold, A. L. and I. A. Guzei, J. Am. Chem. Soc., 1998, 120, 9205.

\section{Conflicts of interest}

